\title{
La Carta de Edificación del P. Alonso D'Aragona escrita por el P. Diego de Boroa
}

\author{
Lucía Page*
}

Recibido: 25 de junio de 2015

Evaluado: 10 de noviembre de 2015

El P. Diego de Boroa (Trujillo, Cáceres, 1585 - San Miguel, 1657) permaneció casi medio siglo en la Provincia Jesuítica del Paraguay. Misionero incansable entre calchaquíes, y sobre todo con los guaraníes en compañía de San Roque González de Santa Cruz, y de una pléyade de misioneros ilustres. Llegó a ser rector de los colegios de Asunción y Córdoba, coronando su carrera eclesiástica como provincial, entre 1634 y $1640^{1}$. Sería larga la enumeración de las conquistas que alcanzó como educador y misionero, pero nos referiremos parcialmente a su labor literaria, de la que nunca llegó a ver un texto suyo impreso. Su publicación más importante es la extensa y detallada Carta Anua del período $1635-1637^{2}$, publicada por primera vez en latín en Lille por el jesuita belga Francisco Hamal en 1642 con 347 páginas. Aunque Sommervovel menciona que el título de una versión alemana se publicó en un catálogo del British Musem de $1877^{3}$.

Escribió Cartas Anuas parciales que cita Astraín y otros textos que publican Cortesão y Helio Vianna, entre unas relaciones e informes que se encuentran inéditos en el ARSI y en el ANCh, y hasta un famoso soneto dedicado a doña Francisca Jesusa Pérez de Bocanegra.

Sin embargo, el P. Boroa se destacó con una importante producción en el género biográfico. En este sentido escribió una relación de los mártires del Caaró, sobre los PP. Diego de Alfaro, Cristóbal de Mendoza, Francisco del Valle, Juan Suárez, Baltasar Seña y un extenso texto sobre Marciel de Lorenzana, entre algunas biografías cortas insertas en su "Elogia Prov. Paraquariae": Barzana, Añasco, D'Aragona y Lorenzana".

\footnotetext{
* Investigadora del programa Jesuitas en Iberoamérica del CIECS-CONICET/UNC. E-mail: pagelucia@hotmail.com. Argentina.

${ }^{1}$ Baptista J. y McNaspy C. 2001: 499.

${ }^{2}$ Leonhardt, 1929: 443-768.

${ }^{3}$ Sommervogel, 1890: 1355.

${ }^{4}$ ARSI, Paraq. 15. Necrológicas 1598-1702, ff. 2-3v.
} 
Precisamente del P. D'Aragona escribe un relato mayor que es el que traigo a continuación.

Escritos que se valieron historiadores como los PP. Del Techo y Lozano, y hasta quizás su contemporáneo y primer historiador del Paraguay, el P. Juan Pastor cuya malograda obra la culminó en 1649.

Su obituario lo tendríamos que encontrar en la Carta Anua del período 16281631 del provincial Vázquez Trujillo, que publica Leonhardt y bien señala que se encuentra incompleta. Por eso queda claro cuando el provincial manifiesta: "Passo también en este $\mathrm{Coll}^{\mathrm{o}}$. a mejor uida el Venerable $\mathrm{P}^{\mathrm{e}}$. Alonso de Aragona celebre por su santidad y trabajos en la promulgacion del $\mathrm{S}^{\text {to }}$. Evangelio que le ocasionaron la muerte. Mas porque en el fin destos annales haremos un sumario de su vida no la recogo en este lugar"

Sin embargo el P. General en carta de 1633 le escribe al provincial Vázquez Trujillo, apenado por la muerte del misionero y escribiendo: "agradesco a V.R. el averme inviado el compendio de su vida, y muerte, que me a sido de particular consuelo" $"$. Indudablemente se refiere al manuscrito del P. Boroa.

La primera biografía del P. D'Aragona que aparece impresa es la del P. Alegambe, quien lo compara con San Luis Gonzaga, mientras le seguirá el P. Del Techo en sus dos obras ${ }^{7}$.

El P. Uriarte escribió que efectivamente la obra del P. Boroa sobre el P. D'Aragona nunca llegó a imprimirse en su versión castellana, aunque aparentemente se publicó en latín con el título de "Epistolam de Vita \& Morte Alphonsi Aragonij Societatis Iesu, Collegio Assumptions diem obiit MDCXXIX", . Pero no conocemos tal impreso. Antonio de León Pinelo ${ }^{9}$ cita una obra en su capítulo dedicado a la historia de varones ilustres y santos de Indias como: "Carta de la Vida, i muerte del P. Alonso de Aragon que murió en la ciudad de Asumpcion en el Rio de la Plata, Año de 1629”. Es decir el mismo título pero en castellano. También lo hace Nicolás Antonio ${ }^{10}$, escribiendo: "Didacus de Boroa. Vida del P. Alonso de Aragon". Finalmente y entre los muchos que citan la obra del P. Boroa cabe mencionar al bibliógrafo jesuita De Backer ${ }^{11}$ quien también menciona esta obra, pero que insistimos, no hemos podido localizarla impresa.

Sí en cambio, encontramos un resumen de este documento publicado en lengua italiana por su coterráneo el P. Saveiro Santagata, continuador de la obra del P. Francesco Schinosi. Jesuitas que surgieron de un proyecto sobre renovación de la historiografía de la Compañía de Jesús, tras las celebraciones del primer centenario de la Orden, dedicándose al estudio histórico de las provincias italianas de Nápoles y Sicilia. Aunque sus frutos se conocieron casi un siglo después.

\footnotetext{
${ }^{5}$ Leonhardt, 1929: 435.

${ }^{6}$ ARSI, Paraq 2. Epist. Gener. 1622-1639, f. 80v.

${ }^{7}$ Del Techo, 1759: 210-213 y Del Techo, 2005: 455

${ }^{8}$ Uriarte, 1914: 258.

${ }^{9}$ León Pinelo, 1738: 840.

${ }^{10}$ Antonio, 1788: 630.

${ }^{11}$ De Backer, 1858: 47.
} 
El P. D'Aragona era profesor de humanidades, latín y hebreo en Nápoles. En Paraguay estuvo 12 años, primero enseñando latín en el Colegio de Asunción, mientras aprendía guaraní. Posteriormente pasó a la reducción de Concepción con el P. Roque González de Santa Cruz, donde permaneció siete años, para luego quedar al frente por dos años de la nueva reducción de San Nicolás. Seguramente con el P. Roque perfeccionó la lengua, que incluso enseñó en San Nicolás al compañero de martirio, el P. Juan del Castillo. D'Aragona poco se relacionaba con los españoles y no mucho sabía de la lengua de Castilla, pues siempre prefirió estar con los indios ${ }^{12}$.

Tuvo una úlcera en la boca, tal vez cancerosa como bien señalan desde Del Techo a Meliá, que lo llevó a curarse a Asunción donde finalmente muere, antes de recibir la patente de rector del colegio de Asunción que enviaba de Roma el general Vitelleschi.

El P. Meliá expresa que junto a Montoya fue por entonces uno de los principales gramáticos de la lengua guaraní. Incluso el mismo Alegambe, en 1643, le atribuye seis obras $^{13}$, aunque como bien señala Meliá no se tratarían de obras concretas sino diversos géneros de trabajos lingüísticos que realizó y que solo se publicó la Breve introducción, pues el resto se encontraría perdido. Trabajo que Meliá lo rescata del Colegio del Salvador de Buenos Aires y publica. Sabemos también que quizás una copia u otra obra similar fue llevada por el procurador Gaspar Sobrino a Roma, para solicitar autorización a los fines de su publicación, aunque al presentársela al P. general lo hizo despectivamente, expresando que el trabajo "se hizo algo de priesa y podria ser que no estubiese con la perfeccion que se desea"14. Pues es comprensible la negativa del general para su publicación.

Volviendo a la biografía que escribe el P. Boroa, ésta se encuentra encuadernada en el tomo señalado anteriormente. Su apretada encuadernación no permite ver los renglones completos de los folios izquierdos, pero el resto se encuentra en buen estado de conservación. Es entonces este texto el primero del género biográfico que se publica del P. Diego de Boroa.

\section{Pax Christi Via}

A los dies de Julio de este año de 1629, fiesta de la Santissima Trinidad a las 8 de la noche, fue nuestro Señor servido de llevar para si en este collegio de la Assumpcion al padre Alonso de Aragona profeso de 4 votos natural de la ciudad de Napoles, de hedad de 44 años, y 27 de Compañía, criose desde niño con grande recogimiento, y fue recibido en aquella ciudad en la Compañia, correindo la carrera de noviciado, y estudios no solo con grande exemplo, y edificacion de todos, pero con grande, y aventajado nombre de santidad, en tanto grado, que cotejaba con la de los

\footnotetext{
${ }^{12}$ McNaspy y Storni, 2001: 1032 y Storni, 1979: 18.

13 1-Vocabularium ingens duabus partibus comprehensum, 2-De Linguae Guaránae particulis, quibus nimirùm omnis eius ornatus definitur, 3-Praecepta Syntaxeos, 4-Sermones ad populum, 5-Dialogos de Sacramentis, et aliis fidei Mysteriis y 6-Cantiones perelegantes de iisdem (Alegambe, 1643: 16).

${ }^{14}$ Morales, 2005: 349.
} 
nuestros, era tenida por muy semejante a la del P. Luis Gonçaga ${ }^{15}$, pues uno de los Padres mas graves del collegio de Napoles, dixo un dia con estas palabras según me ha referido quien las oyo, yo conocí al P. Luis Gonçaga, y su trato y modo de proceder del Padre Alonso es muy parecido y semejante a el y cotejada con los que vivian entonces corria las parejas al parecer de todos con otro padre de raro exemplo de virtud, y santidad de aquel collegio, cuyo nombre se calla por ser vivo. De suerte, que los dos se llevaban los ojos, y hacían raya entre los demás que alli avia, que por ser el collegio de Napoles de los mayores, y mas fervorosos y observantes de la Compañía esto solo bastaría por una grande alabança del Buen Padre Alonso de Aragona.

En tiempo de sus estudios, y despues hasta que vino a las indias, se ocupo en obras dignas de su espíritu, en visitar carceles y hospitales, y fue uno de los que reformaron, y redujeron a bien vivir la carcel de la vicaría de Napoles, atrayéndolos a la virtud, y reduciendolos de gente rota y descompuesta al temos de dios, y frequencia de sacramentos, mediante una congregacion, que fundo en la cárcel misma para ese fin. Tubo a su cargo otra congregacion de oficiales, la qual tenia también concertada, y aficionada, quanto mostro el sentimiento que hiço de su venida a las ybdias. Leyo públicamente Hebreo en aquel collegio con mucha satsfacion, por su grande erudicion y doctrina, y fue Prefecto, o maestro de los Hermanos de la Compañía del quadrienio, mostrando su mucho espíritu y amor, y blandura en ganarlos, exortarlos, y alentarlos a la virtud, y perfeccion, y su entereça en reprehenderlos, y darles penitencia por sus faltas.

Por ese tiempo, que fue el año de 1616 llego a Italia el Padre Juan de Viana ${ }^{16}$ de santa memoria Procurador desta Provincia del Paraguay con animo de traer Padres de Europa a la conversion de muchas Provincias de ynfieles, que por falta de doctrina, y quien se la diesse perecia miserablemente en su infidelidad, y como el Padre Alonso de Aragona tubo noticia de necesidad tan extrema, se movió tocado de nuestro Señor que le llamava a atravesar el mar mediterraneo, y oceano para venir a esta Provincia [ ] tan heroica, como es Reducir las almas a su criador $^{17}$. Paso a España en las galeras de Napoles, librandole nuestro Señor de su evidente Peligro del naufragio, que amenaçava a todos los de la armada: y en las galeras, y en Castilla, y Portugal dio a todos los de la Compañía, y fuera della raro exemplo, y suavissimo olor de sus virtudes. Embarcose en Lisboa $^{18}$ a 4 de Noviembre, de 1616 día de S. Carlos, a quien trajeron por patrón del viaje, y con su intercession le tubieron muy feliz, librandolos nuestro Señor de una horrible tempestad antes de llegar a la Bahia, guardando este religioso varon en el navio el mesmo tenor de vida, recogimiento, y compostura, que en tierra, antes por la

\footnotetext{
${ }^{15}$ Esta comparación la expresa primero Alegambe (1643: 16) y luego Del Techo (2005: 455), agregando este último que junto a su coterráneo P. Vicente Carafa, general entre 1646 y 1649, alcanzarían el mismo grado de perfección.

${ }^{16}$ El P. Juan de Viana (Viana, Navarra, 1565-Córdoba, 1623) ingresó a la Compañía de Jesús de la provincia de Castilla en 1585, llegando a América en 1595. Profesó su cuarto voto en Salta en 1602, siendo electo procurador en Europa en 1614, regresando casi tres años después (Storni, 1980: 302-303).

${ }^{17}$ El P. Meliá (1979) proporciona la noticia que el P. D'Aragona era hijo de Pompelio D'Aragona y Catalina D'Aurea, extrayendo esos datos de un catálogo trienal, que no consigna el P. Boroa. Al verificar el mismo documento, encontramos que también se mencionan los compañeros de la provincia de Nápoles que embarcaron en la barra de Lisboa, el 2 de noviembre de 1616, con el procurador Juan de Viana y su compañero el H. Bernardo Rodríguez. De tal manera que de la provincia de Nápoles también fueron de la partida los PP. Mario Falcone, Pedro Hortencio Sabalone, Juan Bautista Sansone, Claudio Royer, José Oreggi y Pedro Comentali (ARSI, Paq 4.1, Catal. Trien. 1610-1660, f. 36).

${ }^{18}$ Una relación de este viaje y datos biográficos del P. Viana en Page, 2008: 503-513. La biografía más completa en Del Techo, 1759: 146-148.
} 
estrechura del lugar, y incomodidades de la navegacion se dava mas a conocer, y estimar su gran virtud, estirándole en tanto el Padre Procurador Juan de Viana, que queriendo saltar en tierra, y salir al collegio de la Compañía de Jhesus de aquel Puerto, dixo a los demas compañeros, quiero llevar conmigo al Padre Alonso de Aragona porque con su virtud me honre.

En la Bahía fueron muy bien recibidos de nuestros Padres, y hospedados con grandissimo amor, y caridad tan grande, que pareciera exesso a quien no conociera las entrañas de amor, y Caridad, con que siempre en Portugal, y en e Brasil reciben aquellos Santos Padres a sus hermanos en e Señor, que vienen a esta Provincia, aviandolos de todo lo necessario de alli se dieron a la bela, y llegaron al Puerto de Buenos ayres a los 16 de febrero, a donde fueron muy bien recibidos del Padre Pedro de Oñate Provincial, que era desta Provincia, el qual vista la virtud, y deseo de Padecer del Padre Alonso, y su aptitud, y aplicacion de aprender lenguas (pues en la quichua, que vino aprendiendo por el navio aprendio tanto, y aproveccho, que confessava ya en ella) le destino, y señalo para las missiones del Paraguay, embiandole primero a este collegio de la Assumpcion, para que en el leyesse latin a los estudiantes, mientras les servia otro maestro, y venido fuesse a emplearse en la conversión de los ynfieles.

En este collegio estubo algunos años edificando a los de casa y admirando a los de fuera con su rara modestia, humildad y charidad, y con las demás virtudes de que nuestro Señor, le avia dotado, emprimiendo su espiritu en aquellos con quien trataba. Enseño a sus discípulos con mucha diligancia letras, pero con mayor virtud, Hiço y entablo aqui con notable fruto la congregacion de nuestra Señora, y con mudança grande de costumbres de los estudiantes hasta el dia de oy tienen memoria de su sancto maestro; con no menor cuidado tubo a su cargo la cofradia de los indios guaranís, aprendiendo su lengua con mucha constancia y trabajo, y acudiendo a sus necessidades con mucha caridad, y amor; hasta que aviendo nuestro Señor abierto la Puerta al Evangelio en la estendida Provincia del Uruay ${ }^{19}$, el año de 1619 y entrado a dar Principio a la conversion de aquella gentilidad el Santo Padre Roque gonçales de Santa Cruz que después fue martiriçado en ella, el Padre Pedro de Oñate, escogio entre todos para aiuda de tan exelente obra al Padre Alonso de Aragona, dándole empressa proporsionada a su gran deseo de padecer en la qual hallo a manos llenas lo que deseaba assi en el trabajo, como en la ocupacion de convertir almas y atraerlas a su [211] a su criador, ayudandole en todo su Santo companero el Padre Roque gonçales a quien miro siempre, como el mismo Padre Alonso dixo como a Sancto, y como a Padre desde el Punto, que le conocio y aunque avia meses que el Santo Padre Roque avia dado principio a la $1^{\text {a }}$ reducion del Uruay de la Concepcion de nuestra Señora ${ }^{20}$, pero como la gente era tan nueva, y [ ] pacio en Recebir la fee, y juntarse, y formar pueblo; estavan ambos Padres en una chosa pajisa adonde tenian sus [ran]chuelos, y su capilla adonde decian missa, la soledad era mucha, y la falta de las cosas necesarias muy [grandes]

\footnotetext{
${ }^{19}$ Por Uruguay.

${ }^{20}$ La reducción de Nuestra Señora de la Limpia Concepción del Ibitiracuá fue la primera que fundó, en la región del Uruguay, el P. Roque González de Santa Cruz. Una detallada descripción de aquellos momentos se halla en la Carta Anua que firma el P. Oñate en 1620, donde se describe el río y sus habitantes. Pero sobre todo el provincial transcribe dos cartas del P. Boroa que relata la fundación que preparó el mismo P. Boroa quien, en Encarnación de Itapúa, les enseñó a los indios la imagen de los Cuatro Novísimos, obra del H. Berger. Luego el P. Roque, junto al P. Pedro Romero llegaron a la reducción e hicieron su profesión (20 de octubre de 1619). Dieron misa los PP. Roque y Boroa y luego cantaron las letanías y despidieron fervorosamente al P. Roque y lo acompañaron un trecho del camino. Al llegar levantó una cruz y junto a unos indios carpinteros llegados de Itapúa levantó una capilla (Leonhardt, 1919: 216-220).
} 
pues un poco de tasajo llevado del Paraná, era gran regalo sin pan, ni vino ni otra cosa mas que las raíces y leg[ ] con que se sustentan los indios, que a las veces tambien faltavan.

Andavan con mucha diligencia los Padres buscando, y atraiendo los indios, que se les fueron aficionando por su raro [ejem]plo, doctrina y buenas obras, que recibían de los Padres, y por su trato afable, y amoroso, de que se esmerava mucho [el] Padre Alonso de Aragona, haciendose miel dulce a todos, atrayendolos con admirable paciencia, y constancia al[ $\sim$ de suerte que la Reducion se yva llenando de gente, formando pueblo, y levantando casas, con tanta pujança, que [ ] node su fundacion nos juntamos cinco Padres a celebrar la fiesta de la Concepcion en una yglecia nueba, y capaz, que [ha]vian hecho y al segundo año que fue la primera vez, que la visito el Padre Provincial Pedro de Oñate ${ }^{21}$, se celebro la fies[ta] con grande solemnidad, y musica, juntandonos alli 9 de la Compañía y en ese dia dio el Padre Provincial la profession de [cuatro] votos ${ }^{22}$ al Padre Alonso en la iglesia de aquella Reducion con mucho concurso de gente del Pueblo y de la com[arca]. Estos Principios tan felices, y prosperos fueron vísperas de muchos, y grandes trabajos, que Padecio el buen Padre [ ] prueba de su santidad, y paciencia, porque el demonio pesaroso mucho de su Perdida, y de ser hechado de su [ ] antigua temiendo el daño que adelante le amenaçava hiço grande esfuerço para deshaçer aquella $[\sim]$ que avia de ser fundamento y defensa de las demas, tomando por medio de los hechiseros, y casiques aversos a nuestra $\mathrm{Fe}$, assi del Paraná, como del Utuay, y sin darles ocassion alguna los Padres, no solo los comarcanos pero aun los ya $[\sim]$ se yvan volviendo a sus Pueblos, ya antiguos despoblando la reducion ya hecha, a esto se añadio hambre tan[ ] que los traya desatinados de unas partes a otras, a que se siguio la enfermedad Pestilencial de Viruelas, quedando [ ] años, y fue asolando la tierra, y el buen Padre nunca se mostro mas Padre de sus hijos, ni mas contante en estos trabajos [ ] socorrer su necessidad, dava quanto tenía en casa, y quando podía recoger de limosna de las Reduciones del [ ] quitandoselo de la boca para darlo a los Pobres necesitados, y como huyendo de la muerte, se ivan los enfermos [a] los montes, y valles lexos de la Reducion, andava el santo varon con un zelo Apostolico todo el dia, a pie bus[ando] almas por los bosques cathequisando, y baptiçando los gentiles, aiudandoles a priessa para llegar al cielo, e iva t[ ] to, ancioso, y deseoso de la salud de aquellos Pobres, que resuelto, que ves ubo se descalabro muy bien, y demando mucha sang[re] por llegar a socorrer un necessitado destos, y como el trabajo duro tanto tiempo como fue dicho, y era tan execivo, y [ ] estaba tan exausto de penitencias, y trabajos, algunas veces se cayo en tierra de puro cançado, y aun tan [ ] desmayado, que ves ubo, que temieron de su vida; otra vez yendo a una destas obras de charidad cayo en un [ ] y se mojo muy bien, y llegando a la casa del enfermo enbevecido todo en sanarle, se descuydo de si, y se le q[ ] su pobre vestido, diciendo con gran consuelo viendose mojado, y quemado, transivimus per ignem et aquam ${ }^{23}$ pero $1[\sim]$ as muchas no apagaron su charidad, antes la encendieron mas, para ponerse en semejantes trabajos, no pa[ ] de día, ni de noche, enseñando, cathequisando, y sacramentando a los pobres indios, y llego a tanto su caridad que no contentándose de ser medico espiritual de sus almas, con no aver sabido en su vida, ni estudiado medicina [ ] do su extrema necesidad tambien se hiço medico de sus cuerpos, y con ser la enfermedad contagiosa sobre [ ]ra, se llegaba con unas entrañas y amor de verdadero Padre a sangrar los necessitados, aplicandoles medicinas [ ] les, y seguras

\footnotetext{
${ }^{21}$ Solo se conocen tres Cartas Anuas del P. Oñate y estas referencias son posteriores a las mismas.

${ }^{22}$ Fue el 8 de diciembre de 1621 en la reducción de Concepción (Storni, 1980: 76)

${ }^{23}$ Vulgata, Salmos 65.12 V.
} 
con tan buenos successos que volo la fama por toda aquella tierra, maravillandose el buen [Padre] Roque gonçales, y el Padre francisco del Valle ${ }^{24}$ de ver un hombre criado desde niño en el recogimiento de la ora[ción] y de sus estudios, hecho de repente barbero y medico por jesuxristpo, y que en un cuerpo tan flaco, y tan ex[ ] ubiesse un espiritu tan robusto que hiciesse en cierta manera incançable a este Apostolico Varon.

Con tan santas obras, y con muchas, y fervorosas oraciones fue ganando con nuestro Señor el Padre Alonso la con[ ] de aquella gentilidad, la salud y reedificacion de su pueblo desbaratado, y hallandose el en una Junta de [ ] hiço la Reducion del Corpus Xristpo, para tratar de el Remedio de algunos males, que amenaçavan al Paraná, Uruay, entre otras cosas se determino con el ayuda de nuestro Señor, y con parecer del Padre Alonso dos cosas, para q[ ] impedimentos a la Predicacion del Evangelio, la primera, que se procurasse con todos los medios possibles del Parana un gran hechisero $^{25}$, que tenia ynquieto, y alborotado todo el rio, y a punto de perderse, sac[ ] sosegosse. La $2^{\text {a }}$ de sacar un cacique de una ladronera, de a donde avia muy mala vecindad al $[\sim]$ otros aliados suyos, ympidiendo su conversion, y todo se concluyo felismente, quitando este ympedi[mento] de su bien, y el Padre Alonso, que ya estaba de vuelta en el Uruay, aunque solo, se aprovecho de la [ ]miado sin duda de santo zelo, y de la eficacia de la nacion, y confiança en dios, embio por todas aq[uellas] tierras mensajes con mucho valor, y animo, mandando a los yndios, que se redujessen, y a los que avian parado sus casas, que se volviessen a ellas y las poblassen, y ellos lo hicieron, obedeciendo al Padre y se volvió a [edi]ficar, y poblar con mucha mas gente que antes, aquella Reducion de la Concepcion ayudandose el Santo Padre [Ro]que gonçalez, y el Padre Alonso de Aragona, en la conversion, y reducion de aquella gente, con grande espiritu y [211v] y como el oleo Precioso de la caridad, y misericordia á este Santo Varon se derramo tan liberalmente en la ocasion dicha, y en otras muchas, llego su buen olor a las tierras de los ynfieles e la otra vanda del Uruay, y les movio a pedir sacerdote, que les redujesse, y enseñasse, y el que pidieron fue al mismo Padre Alonso, que por acudir a esta necessidad y otras urgentes, estando ya en el Paraná para ir a la Congregacion Provincial, que se hacia en cordoba el año de $26^{26}$ llegandole licencia del Padre Provincial Nicolas duran para ir, o quedarse si la necessidad lo pidiesse el verdadero amador de los indios escogio antes volverse a trabajar, y acudir en tan apretada necessidad al bien de las almas, y aviendo primero el Padre Roque gonçales a enterarse bien de la voluntad de los indios, y escoger puesto dandoles esperanças que luego que viniesse, yo con socorro de Padres que esperaba, al punto les consolaria, como lo hiço. Pues llegado, que fue el Padre diego de Alfaro ${ }^{27}$ Comissario que aora es

${ }^{24}$ El jesuita portugués Francisco del Valle (Miño, 1566-Asunción, 1632) ingresó a la provincia jesuítica de Castilla en 1599, arribando a Buenos Aires en la expedición del P. Romero en 1608 (Storni, 1980: 295).

${ }^{25}$ Se refiere, y más adelante se menciona, al hechicero y cacique de Ijuí, llamado Ñezú, quien celoso ante la creciente influencia de los jesuitas y porque estos se oponían a la poligamia, envió a sus indios a matar a los PP. Roque González de Santa Cruz y Alonso Rodríguez, a los de Candelaria a matar al P. Romero y los de Iyuí al P. D'Aragona y su compañero. En tanto que el cacique Quaraibí envió a otro llamado Araguirá para matar al P. Juan del Castillo.

${ }^{26}$ La Congregación Provincial de 1626 fue convocada por el provincial Nicolás Mastrilli Durán, siendo electo procurador en Europa el P. Gaspar Sobrino, quien personalmente llevó la Carta Anua de 1625 (Leonhardt, 1929: 226).

${ }^{27}$ El jesuita mártir Diego de Alfaro (Panamá, 1596-Caazapá-guazú, 1639), fue hijo del famoso visitador del Río de la Plata, estudiando primero en Lima y luego en Salamanca. Regresó jesuita a Buenos Aires en la expedición del P. Viana en 1617. Continuó sus estudios en Córdoba donde fue profesor de filosofía para pasar a Concepción en 1626. Profesó su cuarto voto en el colegio de Asunción en 1632, cuando era rector del mismo y designado comisario del Santo Oficio. Posteriormente fue superior de las misiones 
del santo officio para emplearse en la conversion del Uruay con la priesa que se dio a aprender la lengua, y hacerse capas de las costumbres de los yndios, dentro de poco tiempo ir el Padre Alonso de Aragona, y el Padre Miguel de Ampuero ${ }^{28}$, Rector que al Presente es de Santa fee a començar la Reducion apalabrada tres leguas de la otra vanda del rio Uruay en el rio Piratiní con titulo de San Nicolas ${ }^{29}$, que es a donde le hallo el Padre Nicolas duran Provincial de esta Provincia yendo en su Compañía ya con 300 yndios alistados que en aquellos pocos meses se avian reducido; y tan fervorosos que a todos nos causo admiracion, ver el alegría, con que salieron a recebir al Padre Provincial, y el afecto, con que un buen numero dellos se dispuso al Santo Baptismo, Baptiçandolos el Padre Provincial con mucho consuelo suyo, y de todos.

Los Palacios reales en que estaba este Bendito Padre en todo semejantes a la Primera Reducion de la Concepcion eran de cosas pajisas, una mejor accomodada, que servia de yglesia, y otra mas baja y humilde, en que estavan los dos compañeros, y por gran cosa hicieron una chosa mas estrecha para recebir al Padre Provincial que no cabía de goço y contento de verse en ella, y de ver la Pobreça tan grande con que allí vivian los Varones Apostolicos, y bien la experimento, quanto llego la hora de comer, pues en un dia de tanto regosijo de su llegada y de la Profession de 4 votos que hiço el Padre Miguel de Ampuero (que escogió hacerla en aquella yglesia pagisa, pudiendo hacerla en otra parte con mas solemnidad) no avia que dar a los huéspedes, ni a dos enfermos, que aquel dia cayeron gravemente, el uno el Santo Padre Roque gonçales, y el otro el mismo Padre Ampuero, que por gran regalo se hallo un gallo, como una piedra, que no le pudieron comer los enfermos.

La esta Reducion, y puesto ymportantissimo, por ser la frontera para a conversion del Uruay, quedo el Santo Padre trabajando apostolicamente, en la Reducion, y conversion de los ynfieles, retrayendolos solicitandoles y buscándolos por todo aquel contorno, sacandolos de sus Pueblos, y madrigueras antiguas con nueba diligencia, y conservandolos con su gran paciencia y mansedumbre, sufriendo sus ymportunidades, y con la buena ayuda del Santo Martir Juan del Castillo que fue su Companero, y discipulo (antes de ir ak Yiui, a donde alcanço la palma del martirio) formaron un gran pueblo de 400 vecinos, y hiço una buena yglecia comoda y capas para enseñarlos, que también le fue ocassion de su ultima enfermedad, con la qual y con eficacia de su oracion aludían a el a ser ynstruidos y muchos ynfieles en los misterios de la fee, y recebir el Santo baptismo, con gran consuelo, y admiracion del Santo Padre Roque gonçales de Santa Cruz, superior de todos, que mostro tanto gusto de ver acudir tanta gente de la doctrina, que le encargo lo llevasse muy adelante, y el verdadero obediente, y caritativo Padre Alonso, se vio obligado y a no solo por la caridad, sino por la obediencia a poner mas esfuerço, que le sufrian sus fuerças naturales a su enseñanza,

entre 1637 y 1639, en plena confrontación con los bandeirantes, de quien recibió un disparo en la frente, siendo sepultado en la misma Concepción junto a los mártires del Caaró (Pérez Alonso, 2001: 75).

${ }^{28}$ El P. Miguel de Ampuero (Lima, 1593-Santiago del Estero, 1654) ingresó a la Compañía de Jesús del Perú en 1610, entrando al Paraguay tres años después. Profesó su cuarto voto en la reducción de San Nicolás en 1627 (Storni, 1980: 12-13).

${ }^{29}$ La reducción de San Nicolás del Piratiní, ubicada a siete leguas de Concepción fue fundada por los PP. Roque González y D’Aragona, el 3 de mayo de 1626. La Carta Anua del P. Mastrilli Durán de 1628 comenta que el P.: "Aragona que le tiene a su cargo (con la confianza que a ganado entre los indios) a hecho algunas entradas por tierra, i a descubierto gente bastante, i buen puesto para fundar otra reducion, que no le dio por entonçes principio" (Leonhardt, 1929: 365). Pero por el ataque bandeirante, San Nicolás fue trasladada en enero de 1632 sobre el arroyo Aguarapucai al occidente del río Uruguay, unida a Apóstoles en febrero de 1652 y separada de ella el 2 de febrero de 1687 estableciéndose en su lugar primitivo del Piratiní. 
y gastava todos los dias cinco horas antes mas que menos, en enseñar, y chatequisar a los ynfieles, Baptiçando a priesa gente de todos estados, que fue ocassion de su muerte, porque con el mucho exercicio de la lengua, hiriéndola con los dientes, se le hiço una llaga pequeña, que el Santo, y mortificado Padre disimulo, jusgando no seria cosa de importancia, pero viendo que se yva haciendo mayor, dio quenta al Padre Roque gonçales, que pasava al caso a recebir la corona, y triumpho de su victoria que no le dio pequeño cuidado, recibiendo a la vuelta el remedio. Pero con ocassion de la llaga y movimientos procedidos del mucho exercicio de cabeça en enseñar, escrivir, y adelantarse en la lengua guaraní, en que era excelente tubo; comen llaga y començo a enfermar, y acrecentarse la calentura lenta, que casi siempre tenía, Purgaronle y sangraronle, y en este estado enfermo le cogió el aviso del Padre Romero ${ }^{30}$, superior, que ahora es de aquellas Reduciones, del dichoso martyrio de los benditos Padres Roque gonçales de Santa Cruz, y Alonso Rodrigues su Compañero, muertos en odio a la fe, por los indios ynfieles del caró, dies u once leguas mas adelante, y cinco de donde estaba el Padre Romero, la qual nueva recibió a los 17 del Noviembre pasado de 1628 años, al tercera del martirio de los Padres con la paz, y sosiego, que si no fuera hombre o no tuviera afectos naturales, porque todos los tenia vendidos, y sujetos a la divina voluntad, y la suya era un mar tranquilo, y un cielo sereno, y finalmente un querer y no querer lo que nuestro Señor queria, o no queria, y con el mismo sosiego recibió el dia siguiente la nueva, de que los de Yiuí avoan muerto al Padre Juan del Castillo, y que venian ya a matarle a el, y a su Compañero. Al principio entendió, que no venían de guerra, pero con la misma Paz se quedo, después que le certificaron venían a matarle, por mandado del hechisero mayor Ñecû, y que trayan los soldados por plumajes las ojas del missal, y breviario del Santo Padre Juan del Castillo, que en su Pueblo, tres leguas de alli dejavan muerto, y su Compañero el Padre Francisco Clavijo ${ }^{31}$, que avia poco, que avia llegado de españa a aquella Reducion, me afirmo, que no hiço en el mas mudança, que sino le ubieran avisado; tanta era la tranquilidad, y paz de su alma, y a los enemigos llegavan a tiro de piedra con horribles voces y alaridos, tocando sus vocinas y trompetas, que atronavan la tierra, ufanos con la Sangre derramada del Santo Padre Juan, teñidas sus flechas, y macanas en su bendita sangre, trayendo los despojos de la ygle [212] Yglecia por tropheo, y asi acercavan A la cruzm que estaba enarbolada junro al templo. Pero el Bendito Padre Alonso temía por que no tenía de que temer, ni trataba de apartarse del peligro, dejando a sus hijos en el, a quien amava [ ] que así. Pero los nuevos hijos, y nuevos Christianos viendo a su Santo Padre en tanto peligro, le pidieron con grande [ ]cia, que se apartase, y se guardase en un montesico, que estava junto a la yglecia, y como viesse un moço valerse [de] animo, que los enemigos se acercavan ya y el Padre se estaba quedo cojio a su buen Padre, y al Padre Clavijo, y metiolos en [el] monte, y apenas avian entrado en el, quando los enemigos de la fee y evangelio con gritos, y alaridos entraron [a la] pobre casa de los Padres buscandolos para matarlos, y

\footnotetext{
${ }^{30}$ El P. Pedro Romero (Sevilla, 1585-Itatín, 1645) conoció al P. Diego de Torres en Cartagena de Indias, quien lo admitió en la Compañía de Jesús y lo llevó al Paraguay, donde fue ordenado por el obispo Trejo y Sanabria en Santiago del Estero. Fue destinado a las misiones de guaraníes en el Guayrá, donde trabajó con los PP. Ruiz de Montoya, Critóbal de Mendoza y con el propio Diego de Boroa, con quien fundó la reducción de Corpus Christi a orillas del Iriamboy. También fundó con el P. Roque las reducciones de Candelaria en 1627, La Cruz y Yapeyú en al año siguiente. Fue superior de las misiones entre 1631 y 1636 e inició el proceso canónico de los mártires del Caaró. Con los ataques paulistas organizó en 1638 el éxodo de los habitantes de San José y posteriormente fue enviado a los itatines donde unos indios paganos lo mataron (Storni, 2001: 1262).

${ }^{31}$ El P. Francisco Clavijo (Córdoba, España, 1599-Corpus, 1664) ingresó a la Compañía de Jesús en Andalucía en 1615, arribando a Buenos Aires en 1628 en la expedición del P. Gaspar Sobrino, profesando sus últimos votos en Candelaria en 1631 (Storni, 1980: 66).
} 
como no los hallaron, començaron con grandes Partidos, ap [ ] a un casique que se los descubriesse y diesse, que al punto serían amigos; Pero el casique correspondio con gravi[ ]mo y fidelidad a dios, a la fee, y al Padre que antes darían la vida que entregarles, y que avian defen[dido la] yglecia, y a sus Padres y haciendo, y diciendo se començaron a retirar hacia fuera, y a flechar los enemigos con tan[to va]lor y esfuerço mas dice, que humano, que con cosa de 18 muchachones se opuso a un exercito victorioso de $y[\sim]$ les, y con la ayuda, que les fue viniendo de las chacaras, les mataron 14 o diesiseis indios,

El buen Padre Alonso viendo, quando entro en el monte el denuedo, y determinacion de los enemigos de la fee, pidio con gra[ ] al glorioso S. Nicolas Patron del Pueblo, e yglecia, que la guardasse y dixole, Santo glorioso guardad nuestra yglecia de la [ ] de los ynfieles, el Padre lo pidió, y el santo lo alcanço, y defendio su yglecia, porque los enemigos aviendole puesto [ ] muchas veces, y por diversas partes, siendo como era toda la cubierta de la yglecia, y casa de paja seca, y en el [ ] verano a las 10 del día, con un sol, que abrasava, no quiso dios nuestro Señor, que emprendiesse en la paja, por [ $]$ diligencias, que hicieron, aplicando tiçones, soplando, y encendiendo los plumajes de Papel, hechando fuego [ ] techo, y sobre la mesa del Padre, sin aver quedado cosa ninguna, no solo quemada, pero ni aun chamuscada, co[ ] soy testigo de vista, que llegue a aquella Reducion, poco despues me lo contaron los mismos que lo vieron $[\sim]$ espanto de tanto raro milagro, y susto por los enemigos que ni en los Padres, ni en la yglecia podían haçer pre[ ] ya yua acudiendo mucha gente, fueronse huyendo con las manos en la cabeça sin aver conseguido [ ] yntento. Pero nuestro Señor por este medio consiguió el suyo, de manifestar su poder, dandoles a entender, que [ ] ]via permitido la muerte de los 3 Santos Padres Compañeros del Padre Alonso, era para fines de su mayor gloria y de[ ] sidernos, los quales, y las yglecias quemadas, y cruces derribadas pudo librar, como libo los Padres, e yglecia del [ ] ny, no con otros exercitos, sino con unos pocos muchachos, porque sus Padres estaban en las labranças guiados de [ ]nos niños de la escuela los padres Alonso, y Clavijo pasaron seguros a vista de los mismos enemigos por un[ ]po de un monte a otro, por donde aquellos niños los llevaban a poner en seguro. Tambien consiguió su fin[ $\sim]$ de coronar al Padre Alonso con corona de martirio mas prolongado, que el de sus compañeros, porque como cami[no a]quel dia tres leguas a pie por malos caminos, enfermo con calentura, flaco, sangrado, y sin comer con aflicion [y] congoja de sus hijos, por los quales yva orando, y clamando al Señor con cuidado, de lo que abrían hecho de la yg[lesia] y de los ornamentos sagrados, eso le bastava por martirio mas doloroso, que la misma muerte entretenido $\mathrm{d}[\sim]$ la con la concideracion, y santa conversacion de sus Compañero el Padre Clavijo acordándose de S. Athanasio, y d[e o]tros Santos Padres que por semejantes cosas andubieron por montes, y espesuras, perseguidos por causa de la fee con[ ] los yvan. Con esta ocasion se le agravo el mal al Santo Confesor por el amor ternissimo, que tenia a Xristpo [ ] y aquellas ovejas de su manada, se dio priessa a volver presto, a recogerlas, y ampararlas, como lo hiço; Aunque [cada] dia le iva creciendo mas la enfermedad de tal suerte, que fue fuerça al Padre Thomas de Ureña ${ }^{32}$ yr a hacerle com[pañía] y suplir en el cuidado de la Reducion, y quando yo llegue tres semanas despues le halle ya muy grande la llaga de la lengua, passe a la Candelaria, y de vuelta (despues de aver dado nuestro Señor a los Xristpianos que defendían [la] fee, y los predicadores della una ynsigne victoria contra los gentiles, que vinieron un dia

${ }^{32}$ El jesuita vallisoletano Tomás de Ureña (Medina de Ríoseco, 1592-Encarnación, 1671) ingresó a la Compañía de Jesús del Paraguay en 1613, profesando sus últimos votos cerca de Natividad en 1626 (Storni, 1980: 291). 
despues de mi llegada a matar al Padre Pedro Romero, y a los que estavamos allí) le despacha a este Collegio de la Assumpcion y luego que llego le vinieron a visitar los señores prebendados de la Cathedral desta ciudad, y las Religiones como a varon de tan conocida santidad el Padre Marciel de Lorençana como Padre de todos, y grande estimador de la virtud, y santidad del Padre Alonso, hiço quantas sugerencias pudo por sanarle, provando diversos medios, pero todos en vano, y en este estado le halle quando volvio de Uruay a este [ ] y hecho un solo de dolores y trabajos, sin poder comer cosa, mas que unos pistos, y con tan grandes valsas, que a las veces le $\mathrm{p}[\sim]$ peligro de otro garle, tenia hinchada la boca sin entenderse ya lo que hablaba, siendo necessario repetir tres, o quatro veces lo que hablava, lo qual hacia el buen Padre con admirable Paciencia, sufrimiento, y fortaleça en el padecer por nuestro Señor teniendose por i [ ] que le sirviese y assi un dia quedarondose desmaiado fuera de la cama, y abraçandose de el hermano Blas su enfermero para hecharle en la cama, le dixo con mucha humildad, y ternura, mi hermano tenga paciencia conmigo, y no se canse de sufrirme, siendo [ ] y avia muy poco que sufrir al Santo, y mortificado varon, pues el mismo se ayudo mas de lo que podía, quanto le duraron las [ ] aunque estaba enfermo hacia sus exercicios espirituales con mucha puntualidad, oya licion especial cada día con grande sentimiento y ternura, levantando el coraçon al Señor con fervorosos affectos, y todo el dia sin duda estava en oracion, el que todo su gusto le tenia [ ] to en dios. Quince días antes de su muerte como vimos la abundancia de humor que le cargava a la garganta, temiendo no le ahogasse de dimos el viatico, y quando le avisaron que se le querían dar, dixo, no es aun tiempo, pero hagan lo que mande la [ ] y en el modo de decirlo mostro hablar con luz superior de cosa que sabia, pues no murio hasta los 15 dias, y a[ ] tarde fiesta de la Santisima Trinidad, en que murio, entrándole yo a ver, me hablo con gran ternura pidiendo perdón $[212 \mathrm{v}]$ de las culpas que no tenía, despidiéndose de mí, vuelto al medico, le agradecio mucho el cuidado, que avia tenido en curarle, y después hablando con el hermano Blas fernandes ${ }^{33}$ su enfermero le dixo, hermano ya se la acaba su trabajo, agradeciéndole con palabras amorosas, del que avia tenido en curarle, que le movyo a lagrimas, llamo al Padre Josep Onejio ${ }^{34}$ su confessor, con quien se confesso generalmente, y pudolo haçer en breve bien ajustadas las cuentas. Recivio con mucha devocion el sacramento de la extrema uncion asistiendo toda la casa, y luego embio con el enfermero al Padre francisco Vasquez Truxillo ${ }^{35}$, Provincial desta Provincia, que avia llegado el dia antes a este Collegio, para que en nombre de su santidad le concediesse la Indulgencia Plenaria de la Compañía el Padre Provincial fue al punto, y se la concedio, y el Santo varon la recibió con lagrimas de sus ojos, con mucha devoción, y affecto, y a las 8 de la noche començo a echar bocanadas de sangre, por la boca en tanta abundancia, que casi lleno una tasa grande, entendiendo los que estábamos presentes piadosamente, que nuestro Señor no quiso privar a este su siervo de la gloria de morir derramando su sangre por su amor, recibiéndole sangre molida a fuerça de trabajos, y cançancio en la enseñansa de los cathecumenos, por caridad y obediencia, que desearon

33 El coadjutor portugués Blas Fernandes (Oporto, 1600-Encarnación de Itapúa, 1665) ingresó a la Compañía de Jesús de la provincia del Paraguay en 1617, profesando sus últimos votos en Asunción una década después (Storni, 1980: 96).

${ }^{34}$ Se refiere al jesuita italiano José Oreggi (Santa Sofía, 1588-San Javier, 1664), quien ingresó a la Compañía de Jesús en Roma en 1606. Seguramente allí fue reclutado por el P. Viana, con quien llegó a Buenos Aires en 1617. Profesó su cuarto voto en Asunción en 1626 (Storni, 1980: 206).

${ }^{35}$ El P. Francisco Vázquez Trujillo (Cáceres, 1571-Córdoba (Arg.) 1652) ingresó al noviciado de Lima en 1588, ingresando al Paraguay por Chile en 1607, profesando su cuarto voto al año siguiente en Santiago de Chile. Fue electo Procurador en la Congregación de 1620 que presidió el P. Pedro de Oñate, regresando dos años después. En 1629 fue electo provincial, falleciendo en Córdoba el 24 de agosto de 1652 (Storni, 1980: 298). 
derramar los enemigos de la fee meses antes en el Piratini, en odio de la fee, que predicaron.

A la mañana siguiente el Señor gobernador deste obispado, y todo el cavildo ecclesiastico embio a ofrecerse para decir la missa, y haçer el entierro, como se hiço viniendo el clero con cruz alta ${ }^{36}$. Dixo la missa el Señor Governador episcopal, acudiendo todas las religiones, y el Señor governador desta Provincia ${ }^{37}$ por su magestad y toda la ciudad con mucho affecto. Esto es como un honor de la dichosa y felicissima carrera, que este siervo del Señor Santo Sacerdote, y predicador Apostolico dio en este mundo hasta llegar a los montes altos de la gloria, como todos tenemos por cierto pues la corrió tan felismente o por mejor decir volo con ligereça de Paloma, con levantado espiritu, no pegándose a la tierra de sus afectos, levantandose siempre assi sobrexitado con las alas ligeras de la oracion y contemplacion, y de otras altissimas, y excelentes virtudes, que aunque el Santo Padre las encubria mucho, como era luz aunque escondio mucho, no pudo encubrirlo todo, y solo tocaré aqui algunas cosas quanto sufre la brevedad de carta dexando larga narracion aqui en escriviere su historia. Su oracion fue altissima, y muy frequente, a lo menos el tiempo que le davan lugar la caridad, y obediencia, y en ella era muy yllustrado de nuestro Señor, recibiendo en su purissima alma como en espejo claro los rayos de la divina luz, y reciviala tan frequentemente, que faltándole por mayo de 1624, como ello declara en un librito secreto, que después de su muerte vino a mis manos, se congojo al pareçer como de cosa nueva, y nuestro Señor le dio a sentir, que con aquello aprovechava en espiritu, y que no extralasse el no perseverar en un estado de luz siempre en esta vida, porque esa olia a amor propio, y que le convenía sentir la amargura de la sequedad, y saco del mismo librito que el mismo año algunos meses despues, le avia nuestro Señor, y a la dulçura de su divina luz, porque en medio de las ocupaciones graves, y de los ministerios con los yndios sentía inclinación, gusto, y consuelo en la oracion, y contemplacion, y trato con nuestro Señor, gustando de privar a los sentidos de su proprio gusto, en el recogimiento interior de la oracion, y en otra ocassion dice, que le alumbro nuestro Señor para exercitar la voluntad en la oracion conforme a su divina voluntad, mejorándole con su divina, yllustracion el modo de obrar, que antes tenía. En ella se terminava a vençer con valor la dificultad del exercicio, y practica de los buenos propósitos, que le dava pues suele acongtecer, recibirle con gusto, y exercitarse con dolor.

Por este medio de la eficas oracion abançava lo que queria de nuestro Señor, como tengo por cierto, que su oracion muy principalmente alcanço de la divina magestad, la conversion de los indios del Yruay, que tan reveldes, y duros estuvieron casi espacio de 7 años, que fueron los años de la estirilidad, siguiéndose tanta abundancia de mies, como de 4 años a esta parte vemos que se coje. A esta eficacia de su oracion (como ya dixe se atribuye el aver el Señor librado la yglecia y casa de Paja del fuego que le procuraron emprender los enemigos de la fee, ya y mucho fundamento para ello, pues nos consta que el Padre se lo suplico a nuestro Señor y sabemos, que el mismo Padre en otra ocassion semejante milagrosamente (al sentir de todos los que estavamos en las missiones entonces) atajo un gran fuego, que venía, a quemar los materiales juntos que tenía juntos para edificar la iglesia de la Concepcion de Uruay, y fue el caso, que se emprendió el fuego en un gran pajonal, que estaba cerca de la madera, y un viento furioso traya la llama volando, ya cercandose, ya a los palos, y

\footnotetext{
${ }^{36} \mathrm{O}$ cruz procesional que se eleva sobre una pértiga que sostiene y lleva el crucífero.

37 Se refiere a Luis de Céspedes García Xería, gobernador del Paraguay entre 1628 y 1633. Un cuestionado mandatario que llegó a ser sospechado de complicidad con los portugueses ante la destrucción producida por los bandeirantes. Por tal motivo fue destituido y enviado a Charcas.
} 
cañas para abraçarlos, procurando en vano alguna poca gente que de allí estava atajar, o dividri el fuego, el Santo varon viendo que era ympossible, y que le faltavan medios humanos, se hinco de rodillas y con afecto de hijo oro a la serenissima Virgen, y con grande afecto le dixo, señora mirad por la medera, y materiales de una yglesia, no permitáis que se queme: cosa milagrosa al punto se volvió el viento, y aparto el fuego, y la madera, y cañas, quedo sin detrimento con admiracion de todos, y fue tenido por manifiesto milagro, y el que fue poderoso para alcançar con sus oraciones, lo que pedia en la tierra, no dudo, que lo es mas en el cielo, y que desde alla esta ayudando a sus hermanos y la conversion de los indios del Uruay, que tanto quiso, y que tiene a su cargo sus negocios, de que tenemos muy ciertas premissas, porque como vi, que se le iva acercando el dia, en que cara a cara avia de ver nuestro Señor, le pedi con encarecimiento, que le suplicasse sobre una cosa de mucha ymportancia, para el bien del Uruay, prometiome hacerlo asegurándome que no succedería lo que me recelava, y poco después de su transito, se hecho de ver la eficacia, con que oro, y negocio con nuestro Señor.

Era devotissimo de la Santissima Virgen nuestra Señora, gastava largos ratos de oracion de rodillas, delante de su ymagen ynvocava su favor, y auxilio con palabras ternissimas, que tenía escritas en un papel en su breviario, junto con la oferta de esclavitud, que se hiço el año de 1602, en Napoles, con otras palabras de ternissimo affecto como de hijo a madre y el que era tan affecto a la madre, lo era a su hijo, y dulcissimo Jhesus, de cuyo nombre, y propiedades tenia en su librito secreto un ternissimo himno, sobre el qual tenia sin duda sus ratos de oron como el mismo Padre lo dice al margen.

Este trato tan familiar con nuestra Señora nacía de íntimo amor, que tenía a su magestad, gustando tratar con su amado y deseando haçer muchas cosas en su servicio. De aqui nacia el amor tan encendido del bien de los Proximos, el buscarlos a las veces con peligros manifiestos de su vida, como muy en particular le sucedio, yendo al Yiuy con ansia de redu[213] Reducir, y convertir al gran hechicero Ñeçû, que le recibió muy mal en su pueblo, y falto poco para ganar el [ ] Padre, por la mano a sus Santos Compañeros, Roque, Alonso, y Juan, que este mismo hechicero (como ya dixe) mando $[\sim]$ tricar, cinco meses despues, ni el mal tratamiento que le hiço fue bastante para entibiar su caridad, antes ynsto con[ ] Roque tanto, que le ganasse la voluntad, y le diesse Padre que no paso asta alcançarlo, si bien el no se aprovecho de la [ ] tes se cego con ella, y la procuro apagar, quitando la vida a su buen Padre Juan del Castillo. Esta caridad, y a $[\sim]$ dexava Reposar, ni quietar buscando medios, con que sacar los yndios de sus peccados, y de su ynfidelidad, y grande [y ver]daderamente grande y encendido era el amor, que le acarreaba, y obligava con perdida de su salud, y vida, a estar horas cada dia (como apunte) cathequiçando y preparando aquella gnete ruda, e ignorante, para que recibiesen a[ ] gran bien de sus almas la vida espiritual dellas, por el Santo baptismo, ni se estendia su caridad a curar solo de sus [ ] pero también de sus cuerpos como esta dicho, curandolos en sus enfermedades, por asquerosas, que fuessen y siempre el mismo, pues estando ya en este collegio con la enfermedad de la muerte, viendo a un muchacho lleno de llagas a[ ] sas, se las lavava con sus propias manos, y limpiava, y curava con amor, y caridad, como quien mirava a Xristpo [ ] en el enfermo, y que maravilla hiciesse esto, el que tubo charidad para amar al otro, que al principio de la Reducion de la Concepcion puso las manos en el, arremetiendole a los pies, para dar con el un batacazo en tierra, para [ ] tarle o matarle, llamando en su ayuda otros muchachos; y la vengança, que el buen Padre Alonso tomo del fue [ ] en amar, y querer bien, a quien le hiço mal, enseñandole con especial cuydado sobre todos los demás. 
Bien podemos decir, que este buen Padre tubo don de Profecia, y assi lo sentía el Santo Padre Roque gonçalez, y otros de [sus com]pañeros, y mostrasse esto ser assi, pues aviendo muchas raçones para entender, que no avia de venir el año Pas[ ] Padre Procurador Gaspar Sobrino ${ }^{38}$, y sus compañeros el constantemente dixo que sí, y lo que es mas, con su loqucion profetica [ ] que ya avia venido y no tardo mucho el aviso de Buenos ayres, que confirmo ser assi verdad. Esrando [ ] ]torce leguas de Itapua en su Reducion de la Concepcion, escrivio al Padre Thomas de Ureña, que Preguntasse al Padre Pedro [ ] como le avia ydo en dia antes con la tempestad; y no sin misterio, pues en aquella Reducion avia caido un rayo en casa, en que hiço daño, y por ventura no fue mayor por las oraciones del Padre y otras cosas decía, que despues [ ] en ellas se hallaba ser assi.

Era muy misericordioso con los pobres, y por eso en Napoles le encargaron repartir las limosnas a los pobres en la portería, y en las Reducciones tubo a manos llenas, en que exercitarse en estas obras dando quanto, avía en casa, aunque mucha falta, especialmente a los enfermos, y quando venía por el río a curarse, hiço pedaços la freçada, que traya y [ ]dio a los muchachos, que le venian ayudando, no por eso le faltava nuestro Señor en sus necessidades antes le socorr[ ] liberalmente en ellas, teniendo muy en el coraçon lo que tenía en un papel escrito, sacado del cap. 28 de los Pro qui dat pauperibus indigebit, quid explicit deprecantetor su stinebit penuria.

Tubo grande estima de nuestro ynstituto, y para haçerse mas capas del, tenía los libros, en que esta declarado, tenia la[ ]la de sus votos escrita en su breviario, yal pie della tenía estas palabras en cifra, espiritu, corde, Practica, .....[ ] prosequendum, et ad id affici debet, tan quae ad dei dones, et inuenti y lo que tenia escrito en estas palabras lo [ ] verdaderamente en las obras siendo fiel hijo de la Compañía con espiritu, y con el coraçon, y la Practica, de aqui nacia la exactissima observancia de las Reglas guardándolas asta los apices; Nadie le vio jamás haçer contra regl[ ] la Compañía, y por saber, que una de las cosas mas essenciales de nuestro ynstituto, y reglas es, la claridad de la ca[ ] cia con los superiores, en viéndose con ellos derrava lo intimo de su coraçon como agua, teniendo el coraçon en la[ ] como lo experimente muchas veces con harta confussion mia las veces, que fui al Uruay a consolarme con [ $\sim$ viendo en el alma de aquel Santo varon un cielo estrellado, de altissimas, y heroycas virtudes. Ni es [ ] que yo diga esto, Pues el Padre Nicolas duran Provincial desta Provincia la ultima ves $^{39}$ que le tomo quenta des[ ] ciencia por el mes de enero de 1627 en la Reducion de S. Nicolas dixo a los Padres, mirenme mucho a las [ ] Padre Alonso, que no saben el tesoro, que tienen en tenerle, ni le falta a este Padre mas que hacer milagros para confesion de su santidad, y si bien se mira, no le faltan, pues su vida fue un continuo milagro, y bien hecha de ver [ ] estava presente lo mucho que avia, que cabar deste precioso tesoro el buen Padre Provincial con llevar mucha [ ] y aver estado solos dos dias en aquella Reducion de S. Nicolas, fuera de otros largos ratos, gasto una tarde [ ] recreándose en el olor de sus santas virtudes.

${ }^{38}$ El P. Gaspar Sobrino (Alagón, Zaragoza, 1584-Lima, 1656) ingresó a la Compañía de Jesús de la provincia de Aragón en 1601 y a Chile en 1618. Fue procurador del Paraguay en Europa entre 1626 y 1628, provincial de Chile entre 1628 y 1632 y del Nuevo Reino entre 1639 y 1642 (Storni, 1980: 271).

${ }^{39}$ En la Carta Anua del P. Mastrilli Durán que firma a fines de 1628, da cuenta de esa visita expresando un hecho vinculado a lo mal que comían los jesuitas. El P. "Aragona queriendome el hacer un solene combite se redujo a multiplicar los platos de frisole coçidos en agua pura y vaste decir que es cosa cierta que al principio destas reduciones murio santamente de hambre en el Guayra el $\mathrm{P}^{\mathrm{e}}$. Martin Xavier Navarro, y pariente muy cercano del $\mathrm{S} .^{\text {to }}$ de su apellido, y el $\mathrm{P}^{\mathrm{e}}$. Baltasar Seña Catalan de nación tuvo la misma muerte" (Leonhardt, 1929: 265). 
Y por ser Regla, y muy importante a los de la Compañía, que venimos a estas partes que aprendamos la lengua de los indios, tomo tan a pechos el buen Padre el cumplimento della, que no contentandose con saber bien la lengua guarani por amor de dios, y de los yndios, puso los ojos en saberla con exelencia, desentrañando, y sacándolos origenes de los verbos, escriviendo muchos libros para utilidad Publica, de los que se ubieron de ocupar en tan santo y Apostolico ministerio, como son dos partes del vocabulario muy copiosas, un sermonario, un tratado de las partículas, que [ ] to da la elegancia desta lengua y un arte para aprenderla muy erudito, muchas, y muy elegantes canciones [ ] ríos dialogos de misterios y sacramentos de nuestra fee.

Fue muy pobre en todo en el vestido roto, la comida lo que hallava y le davan los yndios, y la primera ves que [ ] el Padre Provincial el Uruay, le recibio, y a los que ybamos con el con unos frisoles, y poco mas tenia en la $2^{\mathrm{a}}$ visita en el Piratini [ ] ymagenes, y cosas de devocion, que traia consigo, que eran de papel mostraba el espiritu de Pbreça y un Xristpo muy de[ ] ya de Italia, le dexo al superior, y quando vino de la mission a este Collegio traya una ropa de cordellate rota, y una sotana [ ] lienço mas blanca que negra sin hallarse en el cosa, que no fuesse de verdadero Pobre.

Su pureça fue Angelica, qual la pide nuestra Regla, ni parecía hombre sino Angel, atribuyendo el Padre, que le confesso y ene[ ][213v]

La providencia divina el averlo hecho en lo ultimo de su vida para que mejor se hechasse de ver la pureça de su alma. En Napoles fue siempre tenido no solo por casto, y pleno sino por Virgen, y hasta aora dura esta forma, y el olor desta purissima açucena en aquel collegio, como lo afirma, quien viene aora de alla, treçe años despues que salio el Padre Alonso, que es mucho en collegio tan grande.

$\mathrm{Su}$ obediencia fue exactissima y no tenía otro querer, y no querer que el del superior, y el que lo fue muchos años y era un santo varon tubo cuidado de exercitarle mucho en esta virtud para mayor merito suyo, y prueba de su exacta obediencia su humildad fue profundissima, y tenia en su librito especiales meditaciones, con que exercitarse, en creciendo en esta virtud, en que fue excelente. Afligiose mucho, sabiendo, que el Padre Provincial Pedro de Oñate lo quería llevar a Cordoba por maestro de novicios ${ }^{40}$, como al contrario se holgo de aver estado, ympedido para ir a la Congregacion Provincial por causa de la conversion de los indios, Porque el Padre Provincial Nicolas duran le tenia ya la patente de nuestro Padre General para el mismo officio; sentia vajamente de si, y que no era para nada, siendo verdad, que tenía muy grandes y superiores talentos, y que afirma quien lo sabe, que si ubiera quedado en su Provincia, hubiera sido Provincial en ella, o servidose del la Compañía en cosas de mucha confiança. Pero el Señor, no le tenia escogido para Provincial sino para Apostol, ni para maestro de novicios, sino para maestro de las gentes, como lo fue, y de la alteça de la Predicacion se abatia a las cosas mas ínfimas, porque su gusto en era exercitarse en cosas humildes, y porque el cabello largo es señal de infidelidad en esta nacion guarany, tenia siempre a mano peine y tixeras, para quitar el cavello assi a los que se convertian como a los ya convertidos, lo qual hacia con sus Proprias manos con mucho gusto.

La mortificación deste Bendito Padre fue muy grande, sufriendo con invencible paciencia, quantas cosas adversas se le offrecian yquantas incomodidades, poneindo en

\footnotetext{
${ }^{40}$ No nos consta que el P. Oñate lo designase, sí lo hizo el general Mutio Vitelleschi, en carta que le envía al provincial Nicolás Mastrilli Durán en 1624. Pero ocupó el cargo el P. Juan de Cereceda (ARSI, Paraq. 2. Epist. Gener. 1622-1639, ff. 28v y 62).
} 
admiracion, no solo a los Padres, que le tratavan mas de cerca, pero a los que le servían, pues comiendole pulgas en tanto extremo, que dexava la camissa llena de sangre, no hacia mas sentimiento, que sino fuera sensible, y lo mismo era de los mosquitos; jamas le oyo nadie, quejarse de adversidad, que le succediesse.

A esta mortificacion interior, y exterior añadia una rigurosissima Penitencia, y no solo ayunava, Pero su vida fue un continuo ayuno, como lo mostraba su rostro consumido, y penitente, a que añadia otras rigurosas penitencias, porque el dia de su muerte declaro un siervo de dios, que lo sabia en secreto, que estando en este Collegio el Padre Alonso, le curaron dos veces las grandes llagas, que se le hacían con las continuas diciplinas, sacando dellas gusanos muy grandes, los quales y la sangrasa enterrava en su aposento para que no se supiesse, y este tenor de vida guardo siempre.

Finalmente cuerpo, espiritu, y affecto todo lo tenia rendido, sujeto, y sacrificado a dios nuestro Señor, y tan ajustado a su Santisima y divina voluntad, y tan indiferente a muerte, y aiuda, que es la cumbre de la Perfeccion, y prueba de la verdadera caridad, y amor de dios, que llegando yo el diciembre pasado de 28 a su Reducion de S. Nicolas, estando como estava ya con el mal de la muerte, le dixo el hermano Blas Fernando que iba conmigo, compadeciéndose de, que propusiesse si servia bien venirse a curar; a lo qual respondió, hermano bien lo sabe el superior, dexemonis gobernar de dios, que yo no pedire nada y volviendo yo alli de 8 o dies dias, sin saber lo que avia pasado con el hermano Blas, le dixe, mi Padre Alonso, resuelto estoy de embiar a Vuestra Reverencia al collegio de la Assumpcion para que le curen, a lo qual me Respondio, mi Padre ningun deseo tengo de ir aparte ninguna, ni de otra cosa, Vuestra Reverencia haga de mi lo que jusgare. Respuesta digna de varon tan santo, tan indiferente, y asido y atado a la divina voluntad, pues viéndose movido, y que su vida era de grande importancia, pues della dependia la espiritual de tantos, quería antes morir, que vivir con algun recelo de aver hecho en algo su voluntad.

Esto es algo de lo mucho, que se podía decir deste Santo y apostolico varon, honra, y gloria, de su Patria, de la Provincia que le recivio, y acompaño, y desta que le goço, y de las missiones de la Compañía, en que empleo lo mejor de su vida, haciendo sacrificio della por amor de los yndios, y deste Collegio de la Assumpsion, que viviendo, goço del exemplo de sus virtudes, y muerto goça del tesoro de su santo cuerpo, que estima, como es justo, y aunque del concepto de todos los que se hallaron en su dichosa muerte, de los braços de Xristpo Crucificado (que adorava y besava affectuosissimamente, hasta que espiro) fue goçar de los eternos premios, y corona, con que el mismo Señor le estava aguardando, para galardonarle su santa vida, y trabajos, con todo es bien cumplir con la obligacion de los Santos sacrificios de nuestra Regla y io, me encomiendo en los de Reales de la Assumpcion, y octubre de 1629.

Diego de Boroa, Rector de la Assumpcion

\section{Bibliografía}

Alegambe, Philippus (1643), Bibliotheca Scriptorum Societatis Jesu Post excusum Anno 1608 Catalogum Petri Ribedeneirae Nunc hoc novo apparatu librorum ad annum reparatae salutis 1642 editorum concinnata et illustrium virorum elogiis adornata... Antverpiae (Amberes): Apud Ioannem Mevrsivm. 
Antonio, Nicolao (1788), Hispalensi IC, Bibliotheca Hispana nova sive Hispanorum scriptorum qui ab anno MD. AD MDCLXXXIV. Flouere notitia ..., Volumen 2. Matriti: Apud vidum et heredes Joachimi de Ibarra Typographi Regii.

Aragona, Alonso de (1979) [1620]. "Breve introducción para aprender la lengua guaraní por el P. Alonso de Aragona". Presentación, edición y notas por Bartomeu Meliá SJ", Amerindia 4, pp. 23-61.

Baptista J. y McNaspy C. (2001), "Boroa (Beroa), Diego de. Misionero, superior”, en Charles E. O'Neill y Joaquín María Domínguez Diccionario histórico de la Compañía de Jesús. Biográfico-Temático. Tomo I. Madrid: Universidad Pontificia de Comillas.

De Backer, Agustin et Alois (1858). Bibliotheque des éscrivains de la Compagnie de Jésus ou notices bibliographiques. Quatrieme Série. Liége: Imprimerie de L. Grandmont-Donders.

Del Techo, Nicolás y Orosz, Ladislao (1759). Decades vivorum illustium Paraquaiae Societatis Jesu. Ex Historia ejusdem Provinciae \& aliunde. Authore R.P. Nocilao del techo Ejusdem Societatis Gallo Belga Insulensi. Cum Synopsi Chronologica historiae Paraquariae. Parts Prima. Tyrnaviae: Typis Academicis Societatis Jesu.

Del Techo SI, Nicolás (2005) [1673], Historia de la Provincia del Paraguay de la Compañía de Jesús, Asunción: Centro de Estudios Paraguayos "Antonio Guasch"-FONDEC.

León Pinelo, Antonio de (1738). Epitome de la Bibliotheca oriental, y occidental, náutica, y geográfica de... T. 2. Madrid: en la oficina de Francisco Martínez Abad.

Leonhardt SI, Carlos (1929), Documentos para La Historia Argentina. Tomo XX, Iglesia. Cartas Anuas de la Provincia del Paraguay, Chile y Tucumán de la Compañía de Jesús (1615-1636). Buenos Aires: Facultad de Filosofía y Letras.

McNaspy (†) C. / H. Storni, "D'Aragona (De Aragona), Alonso. Misionero, lingüista”, en Charles E. O'Neill y Joaquín María Domínguez Diccionario histórico de la Compañía de Jesús. Biográfico-Temático. Tomo II. Madrid: Universidad Pontificia de Comillas.

Morales SJ Martín María (2005), A mis manos han llegado. Cartas de los PP. Generales a la Antigua Provincia del Paraguay (1608-1639), Madrid-Roma: Universidad Pontificia de Comillas e Institutum Historicum Societatis Iesu.

Page, Carlos A. (2008), "Dos relaciones inéditas sobre los viajes de Europa a Buenos Aires de los jesuitas Juan de Viana (1616) y Gaspar García (1622”, Revista de la Junta Provincial de Historia de Córdoba, n 25, pp. 503-518.

Pérez Alonso, M. I. (2001), “Alfaro, Diego de. Misionero, víctima de la violencia”, en Charles E. O'Neill y Joaquín María Domínguez, Diccionario histórico de la Compañía de Jesús. Biográfico-Temático. Tomo I. Madrid: Universidad Pontificia de Comillas.

León Pinelo, Antonio de (1738), Epitome de la Bibliotheca oriental, y occidental, náutica, y geográfica de... T. 2. Madrid: en la oficina de Francisco Martínez Abad. 
Santagata, Saverio (1757), Istoria della Compagnia di Gesí appartenente al Regno di Napoli, Napoli: Nella stamperia di Vicenzo Mazzola, Vol IV, pp 514-524

Sommervogel SJ, Carlos (1890), Bibliotheque de la Compagnie de Jésus. Tome I, Bruselas-París.

Storni SJ, Hugo (2001), "Romero, Pedro. Misionero, víctima de la violencia", en Charles E. O'Neill y Joaquín María Domínguez, Diccionario histórico de la Compañía de Jesús. Biográfico-Temático. Tomo IV. Madrid: Universidad Pontificia de Comillas.

— (1979), “Jesuitas italianos en el Río de la Plata”, AHSI 48 - 18.

Uriarte, P. J. Eug. (1914), Catálogo razonado de obras anónimas y seudónimas de autores de la Compañía de Jesús pertenecientes á la antigua asistencia española. T. 4. Madrid: Establecimiento tipográfico "Sucesores de Rivadenyra". 